\title{
O PROBLEMA DA PARCERIA ENTRE O PARQUE NACIONAL DO MONTE RORAIMA E O POVO INDÍGENA INGARIKÓ NA AMAZÔNIA SETENTRIONAL
}

Oseias Cordeiro Sartori ${ }^{1}$ Henrique dos Santos Pereira²

Resumo: Essa reflexão se concentra no problema da parceria entre o órgão responsável pela gestão do Parque Nacional do Monte Roraima e o povo indígena Ingarikó. As dificuldades impostas pelo abandono da discussão sobre a segurança alimentar, com consequências negativas para a proteção do ambiente e a qualidade de vida indígena, conferem relevância ao estudo. Para subsidiar a reflexão, foram empregadas estratégias de levantamento bibliográfico, análise documental, entrevistas e observações. Os resultados indicaram que a desconsideração da demanda indígena por segurança alimentar torna a aproximação insuficiente para a conciliação dos interesses. Essa situação suscita a adoção de um processo de gestão pautado pela organização conjunta.

Palavras-chave: Parque nacional. Território indígena. Conservação da biodiversidade. Segurança alimentar. Parceria.

\section{THE PROBLEM WITH THE PARTNERSHIP BETWEEN THE MONTE RORAIMA NACIONAL PARK AND THE INGARIKÓ PEOPLE IN THE NORTHEN AMAZON}

Abstract: This reflection focuses on the problem on the partnership between the agency responsible for managing of the Monte Roraima National Park and the Ingarikó People. The difficulties created by the abandonment of the discussion about Food Supplying, with negative consequences for the protection of environment and the quality of indigenous life, make this issue a very important one. In order to help the reflection, strategies of bibliographic survey, document analysis, interviews and observation were done. The results showed that the disregard for the demand for Food Supplying makes the approach insufficient to reconcile the interests. This situation requires the adoption of a management process based by the joint organisation.

Keywords: National park. Indigenous territory. Conservation. Food supplying. Partnership.

\section{EL PROBLEMA DE LA SOCIEDAD ENTRE EL PARQUE NACIONAL MONTE RORAIMA Y EL PUEBLO INGARIKÓ EN EL AMAZONA NORTE}

Resumen: Esta reflexión se centra en el problema de la sociedad establecida entre la agencia responsable por la gestión del Parque Nacional Monte Roraima y el Pueblo Ingarikó. Las dificultades creadas por el abandono de la discussión sobre seguridad alimentícia, con consecuencias negativas para la protección del ambiente y la calidad de vida indígena, le dan relevancia al tema. Para apoyar la reflexión, se emplearon estrategias de encuesta bibliográfica, análisis de documentos, entrevistas y observaciones. Los resultados indicaron que el desprecio de esta demanda indígena por seguridade alimentícia hace que la aproximación sea insuficiente para

\footnotetext{
1 Universidade Federal do Amazonas, Ciências do Ambiente, Manaus, Brasil, oseias.sartori@gmail.com, https://orcid.org/0000-0003-2099-4375

2 Universidade Federal do Amazonas, Ciências do Ambiente, Manaus, Brasil, henrique.pereira.ufam@gmail.com, https://orcid.org/0000-0002-9113-1166
} 
conciliar los intereses. Esta situación requiere la adopción de un proceso de gestión basado en la organización conjunta.

Palabras clave: Parque nacional. Territorio indígena. Conservación. Seguridad alimentícia. Sociedad.

\section{INTRODUÇÃO}

A motivação geopolítica de defesa de um segmento da fronteira do extremo norte do país ensejou a criação do Parque Nacional do Monte Roraima (PNMR) no território ocupado milenarmente por integrantes da família linguística que Frank (2008) chama de Proto-Caribe. Segundo Brasil (1989), o PNMR foi criado pelo Decreto no 97.887, de 28 e junho de 1989. Situado entre as coordenadas geográficas $04^{\circ} 48^{\prime}$ a $05^{\circ} 16^{\prime}$ latitude norte e $60^{\circ} 05^{\prime}$ a $60^{\circ} 44^{\prime}$ longitude oeste, sua área abrange 116 mil hectares do norte da Terra Indígena Raposa Serra do Sol (TIRSS), município de Uiramutã, nordeste do estado de Roraima. Na face leste, os limites da unidade de conservação coincidem com a linha de fronteira que separa o Brasil da Venezuela, enquanto na face norte se limita com a Guiana (Figura 01).

Figura 01- Localização da área de estudo

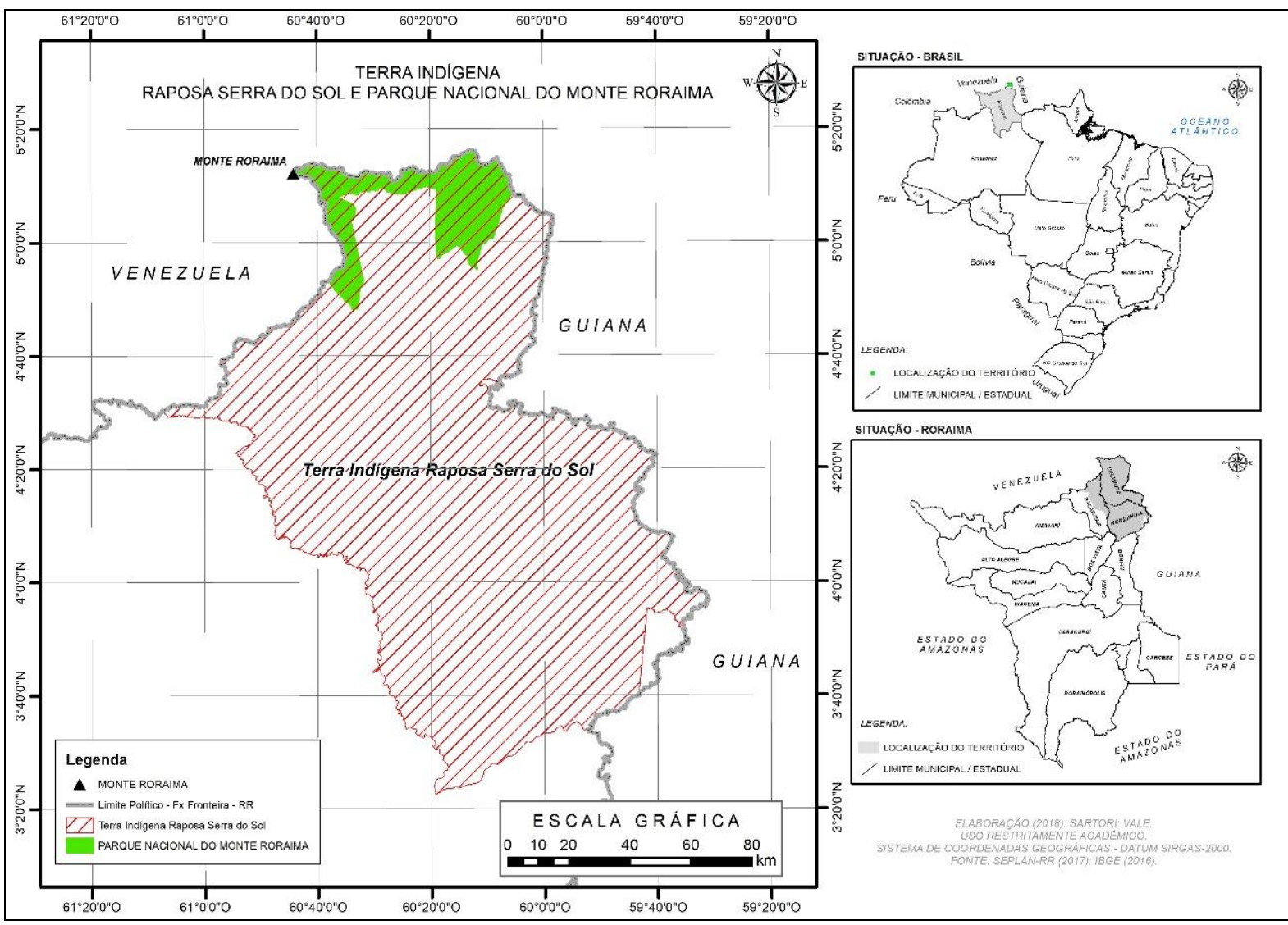

Fonte: Brasil (2018) e Roraima (2017). Elaboração de Fernando Bruno Pinheiro Vale (2018) 
Embora o PNMR tenha sido criado no final da década de 1980, as primeiras providências de implementação da unidade de conservação ocorreram no ano de 1997, quando foi elaborado o termo de referência para a construção do plano de manejo. Somente no ano 2000, quando a proposta de plano de manejo estava quase concluída, foi iniciada a aproximação com o povo Ingarikó.

Como os indígenas estavam enfrentando o problema da insegurança alimentar desde períodos anteriores aos contatos com o órgão ambiental responsável pelo PNMR, as discussões propostas nesse estudo se iniciam pelas principais causas e reações indígenas à redução da disponibilidade de bens naturais. Nas referências ao período posterior ao estabelecimento da parceria com o órgão ambiental, as abordagens perpassam a inclusão e o posterior abandono da discussão sobre a segurança alimentar dos diálogos entre as partes, assim como as mudanças nas relações dos indígenas com o ambiente e a necessidade de um processo de gestão abrangente.

A relevância do tema se manifesta nas implicações da insegurança alimentar com a conservação da biodiversidade e a qualidade de vida do povo Ingarikó. Embora as abordagens se restrinjam a apenas um caso, a imbricação das questões ecológicas e sociais também ocorre nas demais áreas superpostas. Um levantamento realizado por Brasil (2012) indicou a existência de 23 casos de sobreposição envolvendo unidades de conservação de proteção integral federais e territórios indígenas. Esses números refletem a urgência da adoção de processos de gestão mais abrangentes.

A construção dessa reflexão contou com informações oriundas de levantamento bibliográfico, análise documental, entrevistas e observações. Os documentos acessados foram o plano de manejo do PNMR, contido em Brasil (2000), o compêndio denominado SOS Monte Roraima, disposto em Brasil (2004), o Plano de Administração Conjunta, conforme Brasil (2008) e os relatórios das assembleias gerais do povo Ingarikó. Também foram realizadas quarenta e nove entrevistas, sendo quarenta com o povo Ingarikó, quatro com servidores do Instituto Chico Mendes de Conservação da Biodiversidade (ICMBio), três com servidores da Fundação Nacional do Índio (FUNAI) e duas com coordenadores do Conselho Indígena de Roraima (CIR). As entrevistas com os indígenas foram autorizadas previamente pela Comissão Nacional de Ética em Pesquisa (Parecer no 2.255.365) e pela FUNAI (Autorização no 50/AAEP/PRES/2017). Além das consultas e entrevistas, foram realizadas observações de campo nas onze comunidades, 
envolvendo seis expedições, cada uma delas com duração de aproximadamente quinze dias, entre os anos de 2017 e 2018.

\section{PRINCIPAIS CAUSAS E REAÇÕES INDÍGENAS À INSEGURANÇA ALIMENTAR}

Entre os diversos embates empreendidos pelo povo Ingarikó ao longo da sua história, o combate à insegurança alimentar, iniciado na década de 1980, passou a exigir cada vez mais atenção e desafiar, com ímpeto crescente, as estratégias tradicionais de enfrentamento. Os fatores impulsionadores da insegurança alimentar, representados principalmente pelo crescimento populacional e pela sedentarização, foram ensejados por aspectos como a expansão do território, a medicina dos brancos e as estratégias de defesa do espaço vivido.

\section{Principais causas do crescimento populacional}

A história do povo Ingarikó teve início num contexto de conflitos interétnicos que obrigou esses indígenas a buscarem refúgio na floresta da cordilheira de Pacaraima e optarem pelo controle populacional como estratégia de defesa. Ingaricó (2012) menciona o limite de dois filhos por família nesse período, indicando o conhecimento de métodos contraceptivos.

A situação de confinamento e esconderijo começou a mudar quando esses originários retomaram antigas estratégias de defesa do território empregadas pelos habitantes do entorno do Monte Roraima, tais como os ataques de canaimé. Para Whitehead (2002), o termo canaimé se refere a uma prática de mutilação ritual presente entre grupos da região Circum-Roraima. A figura do canaimé alude a um assassino declarado que promove uma morte horrível e persistente. Suas práticas podem incluir a perfuração da língua com presas de cobra e retirada dos músculos anais. Assim, antes de morrer a vítima torna-se incapaz de tomar o sustento por via oral, além de se tornar incontinente. A desidratação aguda provocada pela diarreia leva à morte. Em seus estudos, o autor pôde confirmar que canaimé é uma experiência real, presente na vida cotidiana dos indígenas da região CircumRoraima.

Segundo Cruz (2005), a associação entre as práticas de canaimé e a antropofagia tornou o povo Ingarikó respeitado entre as etnias vizinhas, possibilitando a ampliação do território. Essas iniciativas contribuíram com o crescimento populacional. 
Havia, contudo, algumas limitações impostas por doenças contagiosas e a mortalidade infantil. Segundo a Fundação Ecoamazônia (2018), a combinação desses fatores provocou expressivas oscilações no tamanho da população durante o período compreendido entre os anos de 1943 e 1995. Cabe ressaltar que as oscilações registradas aqui também se devem às diferentes fontes utilizadas pela Fundação Ecoamazônia (2018), permitindo a consideração desses dados apenas como estimativas (Gráfico 01).

Gráfico 01- Estimativas sobre o tamanho da população Ingarikó entre 1943 e 1995

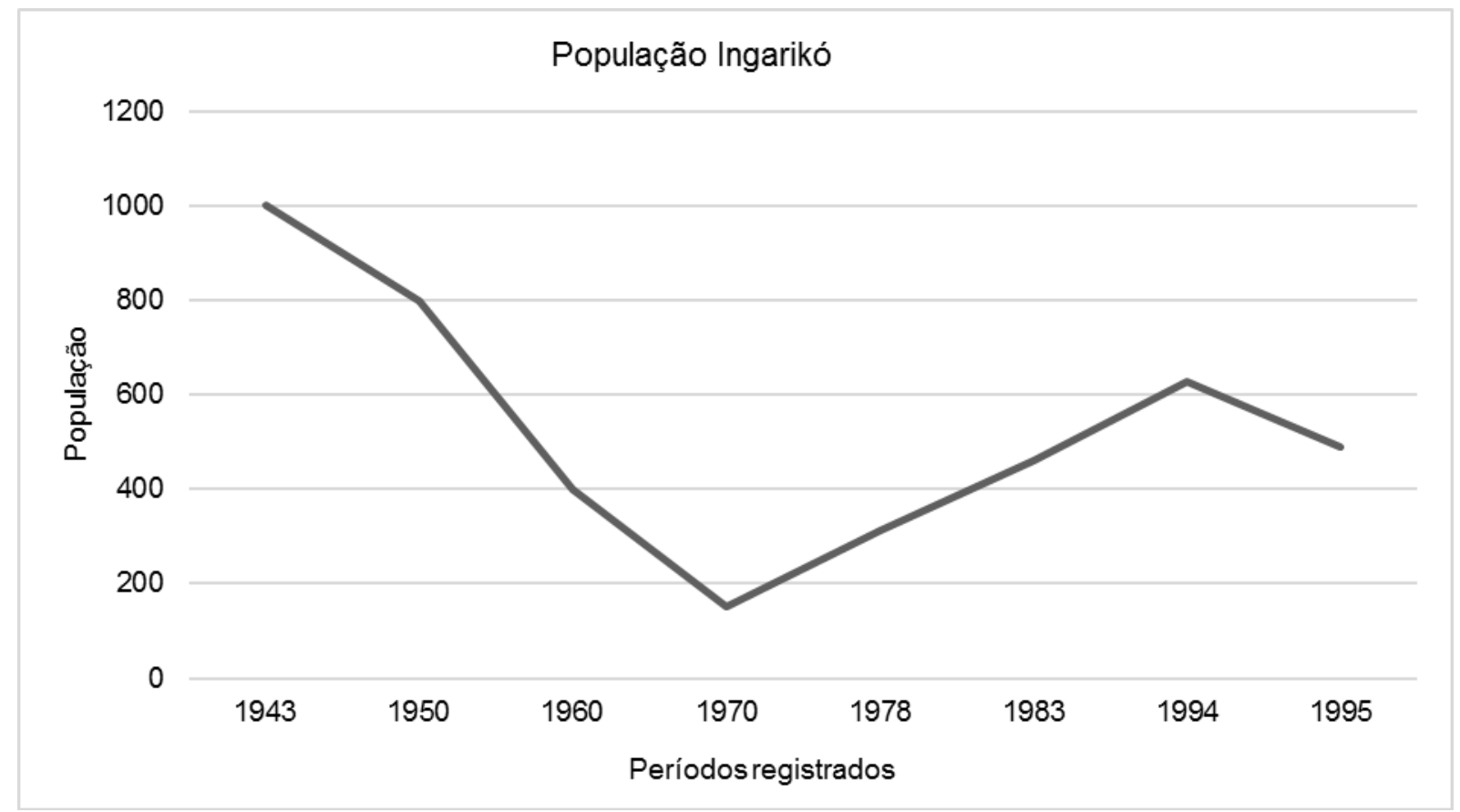

Fonte: Fundação Ecoamazônia (2018)

Segundo Cruz (2005), a década de 1970 marcou o início das visitas da FUNAI ao território Ingarikó e a atuação das equipes volantes de saúde. A Entrevistada 45, ex-integrante da equipe de saúde da FUNAI, lembrou de sua atuação direta no combate a surtos de coqueluche e pneumonia no território Ingarikó na década de 1980. Não descartando a hipótese de Pagliaro (2005), sobre o aumento da resistência indígena a determinados agentes infecciosos, a assistência médica da FUNAI parece ter influenciado substancialmente a redução das oscilações no tamanho da população.

\section{Antecedentes da sedentarização}

Segundo Ingaricó (2008), a sedentarização foi provocada predominantemente pela escolarização. A ideia de utilizar a comunicação com os brancos como estratégia de defesa do território levou os indígenas a aceitarem a 
proposta de missionários evangélicos e autorizarem a implantação de uma escola na comunidade Serra do Sol.

Segundo Teixeira (2008), a primeira escola começou a funcionar no ano de 1974, tendo o próprio pastor missionário como professor. Após sua desistência no ano seguinte, outros educadores assumiram as atividades, especialmente depois do reconhecimento oficial da escola pelo Decreto do Estado de Roraima no 027, de 24 de agosto de 1977. Com o passar do tempo, os diversos professores que se revezaram na condução das atividades escolares passaram a desfrutar de grande prestígio perante os indígenas e aproveitaram para sugerir algumas mudanças em seu modo de vida.

Segundo Teixeira (2008), o processo de sedentarização teve início quando um dos professores observou que alguns estudantes precisavam caminhar durante quatro horas para chegar à escola. Por conta disso, solicitou que as famílias construíssem casas em locais mais próximos do espaço escolar. Muitos dos que atenderam a solicitação deixaram de viver exclusivamente na mata, junto às suas roças. Essa iniciativa contribuiu com o aumento da densidade demográfica no centro na comunidade.

Enquanto a experiência do ensino formal se desenvolvia na comunidade Serra do Sol, o debate sobre os benefícios e os efeitos negativos da escolarização alcançava todo o povo Ingarikó. As discussões evidenciavam a resistência das lideranças mais antigas à ideia de educação formal pautada no modelo da sociedade envolvente.

Segundo Ingaricó (2012), na comunidade Manalai o líder religioso resistiu durante toda a sua vida à implantação de uma escola. Porém, as lideranças mais jovens da comunidade começaram a se aproximar do movimento indígena e se depararam com a barreira da comunicação.

Segundo Bernilda Ingaricó (2012) e Larangera Ingaricó (2012), essa situação levou os líderes mais jovens a concluírem que a escola poderia ajudar no aprendizado da língua dos brancos, propiciando uma representação adequada do povo. Após a morte do líder mais resistente à escola, várias discussões foram promovidas sobre o tema do ensino formal, levando a comunidade Manalai a demandar a implantação de uma escola. A iniciativa resultou na implantação da Escola Estadual Indígena Sales Ingaricó, no ano de 1994. No ano seguinte, Ingaricó (2018) destaca o início de um processo de escolarização na maioria das comunidades. 
A ampliação da escolarização continuou preocupando os líderes mais antigos, levando um deles a convocar uma reunião com todos os tuxauas no ano de 1997. Conforme Teixeira (2008), durante o encontro foram levantadas questões que suscitaram discussões ainda mais amplas. Assim, no ano de 1999 todo o povo foi convidado a se reunir para discutir o tema da escolarização. Diante do entendimento sobre a importância da escolarização, os Ingarikó optaram pela ampliação do ensino formal.

O aumento do número de escolas estendeu o efeito da sedentarização a todas as comunidades, oferecendo significativa contribuição ao acréscimo da quantidade de famílias que passaram a viver nos centros das comunidades. Esse fenômeno desencadeou a sensação de escassez de alimentos.

\section{Reações indígenas à insegurança alimentar}

A dificuldade crescente de acesso aos alimentos provocou uma recorrência maior dos Ingarikó aos seus líderes espirituais, que eram reconhecidos como guardiões dos conhecimentos simbólicos, mitológicos e religiosos. A explicação para essa atitude pode ser encontrada na própria cosmologia desses indígenas.

Segundo Brasil (2008), os irmãos Makunaimë e Siikî, filhos de Imë, que viviam na Wayaka yek (grande árvore da vida), criaram todas as coisas. Os dois irmãos transformaram plantas e animais em rochas. Para cuidar das rochas-plantas e rochas-animais, criaram os pais e mães das plantas e animais. Muito tempo depois, os pajés e as pessoas de muito conhecimento sobre a cultura e o ambiente conseguiram identificar os pais e mães das plantas e animais e se comunicarem com eles. A aproximação com esses seres conferiu aos líderes espirituais a responsabilidade de garantir a disponibilidade de bens naturais. Nas ocasiões nas quais eram requisitados, tais líderes aproveitavam para transmitir diversas recomendações ao povo, invariavelmente relacionadas com os aspectos culturais e ambientais.

Com a chegada da religião Areruya, considerada por Abreu (2010) um sincretismo religioso, os ensinamentos comumente repassados pelos pajés e pessoas de muito conhecimento cederam algum espaço aos líderes religiosos e suas novas propostas. Entretanto, Rodrigues (2013) menciona a ocorrência de sinergias entre os pressupostos religiosos e o restante da cosmologia Ingarikó, 
compondo uma tríade de lideranças espirituais formada por líderes religiosos, pajés e pessoas de muito conhecimento.

Assim, quando os Ingarikó começaram a identificar os primeiros sinais de redução da disponibilidade de bens naturais, recorreram primeiramente a esses líderes espirituais, mas eles não puderam recuperar a abundância perdida. Segundo a perspectiva de um entrevistado,

\begin{abstract}
Antigamente tinha muita caça porque os velhos tinham conhecimento de trabalhar com a pedra dos animais. Antes tinha muita anta, queixada, catitu... Aí, a maioria desses anciãos morreu. Hoje, tem poucas pessoas que tem conhecimento para trabalhar com essa pedra de animais. Só que a pedra de animais também enfraqueceu (Entrevistado 04).
\end{abstract}

A dificuldade para resolver o problema da escassez por meio dos símbolos, mitos e mágicas suscitou novos sentidos às experiências indígenas. Para Mahfoud e Massimi (2008), os novos sentidos costumam conduzir à transformação das pessoas. Entre os Ingarikó, tais reflexões suscitaram a priorização de estratégias pautadas no empirismo e nas técnicas, conduzindo ao aumento da pressão sobre o patrimônio natural e à valorização crescente do conhecimento dos brancos, tendência abordada por Mlynarz (2008).

Em meio à busca por alternativas de combate à insegurança alimentar, o estabelecimento de uma parceria com o Instituto Brasileiro do Meio Ambiente e dos Recursos Naturais Renováveis (IBAMA) pareceu indicar novos horizontes.

\title{
PARCERIA COM O ÓRGÃO RESPONSÁVEL PELO PARQUE NACIONAL
}

A aproximação entre o IBAMA e o povo Ingarikó, iniciada no ano 2000, se desenvolveu em meio à uma tensão ocasionada pelo uso do patrimônio natural. Depois de seis anos de acirramento da tensão, uma estratégia governamental fez retroceder o conflito socioambiental manifesto a um estágio latente e propiciou a formação de uma parceria focada no alcance dos objetivos de conservação da biodiversidade e melhoria da qualidade de vida indígena na área sobreposta. Não obstante, algumas mudanças nas configurações da realidade provocaram 0 abandono da discussão sobre a segurança alimentar.

\section{Aproximação conflituosa}

Quando alguns líderes do povo Ingarikó foram convidados a participar da oficina de elaboração do plano de manejo do PNMR, não tinham ideia das implicações dessa área protegida em seu território. Durante o evento realizado no primeiro trimestre do ano 2000 , foram comunicados formalmente sobre a existência 
de uma unidade de conservação de proteção integral em seu espaço vivido. Para esses indígenas, o comunicado oficial chegava com mais de uma década de atraso.

Ao compartilharem o assunto geral da oficina com seus pares, puderam levantar diversos questionamentos. Algumas perguntas foram levadas ao povo Macuxi, mas seus vizinhos não puderam responder. Assim, procuraram alguns servidores da FUNAI em busca de respostas. Segundo Lauriola (2011), os indígenas pareciam preocupados com a política preservacionista direcionada ao seu território.

Para Mlynarz (2006), a carência de entendimento sobre o PNMR justificou a realização de uma missão da FUNAI, dedicada a esclarecimentos e registros dos posicionamentos do povo Ingarikó. A ação empreendida entre agosto e setembro de 2000 foi liderada por Martinho A. de Andrade Júnior e Vincenzo M. Lauriola.

Durante as explicações da FUNAI, os Ingarikó não conseguiram vislumbrar qualquer benefício diferente daqueles já oferecidos pelo ambiente, e ainda puderam constatar diversas consequências negativas ao seu modo de vida. Nessas circunstâncias, optaram por manifestar a sua contrariedade à existência da unidade de conservação. Esse posicionamento provocou o estabelecimento de um conflito socioambiental. Segundo a Entrevistada 43,

\footnotetext{
Havia recursos financeiros oriundos de compensação ambiental disponíveis para as primeiras obras no interior do parque nacional. Porém, o acirramento dos conflitos com o povo Ingarikó levou o órgão ambiental a desistir de usar a verba para tal finalidade, direcionando os recursos para outra unidade de conservação (Entrevistada 43).
}

Little (2006) percebe o conflito socioambiental como um conjunto complexo de embates entre partes que podem envolver grupos sociais e o poder público, podendo abarcar elementos cosmológicos, rituais, identitários e morais. Quando ocorre 0 acirramento das tensões, os conflitos socioambientais se tornam manifestos. Depois de algum tempo, pode sobrevir um apaziguamento e as tensões se tornarem latentes. Como não existe a possibilidade de resolução completa do conflito sem a eliminação da sua causa, conforme defende Regalia (2012), o estágio latente não se dissipa, podendo evoluir novamente para um conflito manifesto.

A tensão provocada pelo debate em torno da proteção integral do ambiente e a liberdade de usufruto indígena se prolongou durante cinco anos. Porém, como os diálogos não deixaram de acontecer, o período de conflito manifesto também favoreceu a aproximação entre as partes. 


\section{Inclusão e posterior abandono da discussão sobre a segurança alimentar}

No início do segundo trimestre de 2005, enquanto representantes do órgão ambiental aguardavam a realização da reunião anual agendada pelo povo Ingarikó, a TIRSS foi homologada pelo Decreto de 15 de abril de 2005. Segundo Brasil (2005), o ato oficial que incluiu o território desses originários na referida terra indígena reconheceu a dupla afetação e determinou a elaboração de um plano de gestão conjunta para a área sobreposta.

A determinação legal previa a divisão da responsabilidade da administração do parque nacional entre os Ingarikó e os órgãos federais ambiental e indigenista. Essa estratégia de gestão de conflitos permitiu o exercício da autonomia indígena nos moldes propostos por Pulido (2006), como um tipo de liberdade democrática na qual a vontade se torna capaz de se autodeterminar.

O primeiro exercício de negociação entre as partes aconteceu durante a III Assembleia Geral Extraordinária do Povo Ingarikó, realizada em agosto de 2005. Segundo Mlynarz (2006), logo no discurso de abertura, o presidente do Conselho do Povo Indígena Ingarikó (COPING) expressou sua preocupação em entender como a área sobreposta poderia ser preservada sem alterar o modo de vida indígena. $\mathrm{O}$ representante do IBAMA respondeu que todas as ações institucionais respeitariam a vontade do povo Ingarikó. Por seu turno, o servidor da FUNAI destacou que todas as ações concernentes à gestão do PNMR dependeriam do consentimento dos indígenas.

As respostas dos representantes institucionais foram interpretadas pelos indígenas como o reconhecimento de uma situação especial, na qual a gestão da área superposta teria como pressuposto principal o respeito ao modo de vida indígena. Nessas condições, os Ingarikó assumiram o protagonismo da elaboração do plano de gestão conjunta, chegando a incorporar ao documento o seu próprio plano de vida. Conforme Brasil (2008), cada parágrafo do plano foi pensado para possibilitar o atrelamento da gestão do parque nacional ao cotidiano da vida indígena e suas perspectivas de futuro.

As propostas discutidas durantes três anos compuseram a minuta do Plano Paata Eseru. Contudo, enquanto as diversas instâncias da FUNAI e do ICMBio analisavam o teor do documento, o STF iniciou o julgamento da Petição no 3.388 , que questionava a demarcação da TIRSS. Segundo Rodrigues e Ferreira (2013), o julgamento concluído no ano de 2009 impôs dezenove condicionantes à referida 
terra indígena, incluindo o reconhecimento do ICMBio como o único gestor do PNMR.

Essa determinação foi interpretada pelos indígenas como uma estratégia de exclusão da participação do povo Ingarikó do processo de gestão da área sobreposta. Prevendo a reação indígena, os representantes locais do órgão ambiental evitaram durante alguns anos as referências ao Plano Paata Eseru nos contatos com esses originários. O mesmo silêncio passou a envolver o tema da segurança alimentar, criando, assim, um problema na parceria com os indígenas e obrigando os originários a buscarem soluções por outras vias. Em sua busca, passaram a provocar mudanças nas relações com o ambiente.

\section{Mudanças nas relações com 0 ambiente}

As mudanças suscitadas pela insegurança alimentar passaram a interferir de forma crescente nas experiências de grande parte do povo Ingarikó. Gallois (2007) destaca que determinadas mudanças podem conduzir à perda da memória de algumas experiências. Koselleck (2006) corrobora a afirmação anterior ao destacar que determinadas mudanças podem se impor às experiências.

No caso do povo Ingarikó, a urgência do combate à insegurança alimentar também passou a se refletir na saúde dos indígenas. Dilson Ingaricó (2008) já havia alertado para o tempo muitas vezes prolongado para a percepção das consequências de uma alimentação inadequada. Dez anos depois, as constatações de Secilita Ingaricó (2018) sobre o aumento de casos de desnutrição e doenças oportunistas pareceram confirmar as declarações anteriores.

Diante do agravamento do quadro de insegurança alimentar, algumas mudanças nas relações com 0 ambiente se tornaram mais destacadas, especialmente entre as atividades de caça e pesca, produção de alimentos e as novas estratégias de ampliação da oferta de alimentos.

Atividades de caça e pesca

Com o agravamento da situação de insegurança alimentar, o aumento da pressão sobre a fauna se tornou inevitável. Embora Dorst (1973) defenda que nenhum depredador tem interesse em exterminar suas presas, um avanço maior sobre os estoques se tornou a única alternativa de obtenção de proteína para uma parte significativa da população Ingarikó. 
Falcão (2016) ressalta um alto índice de Beribéri entre os Ingarikó, doença causada pela falta de vitamina B1. Essa informação faz lembrar as considerações de Butto (2005), sobre os reflexos da insuficiência alimentar nos níveis de desnutrição e doenças oportunistas entre vários povos indígenas.

Para fundamentar a discussão sobre o aumento do esforço de caça, foi perguntado aos indígenas se havia mais facilidade para caçar e pescar no tempo dos pais e avós. Todos os entrevistados responderam afirmativamente. Quando questionado sobre o tema, o Entrevistado 07 respondeu que "a caça e a pesca está diminuindo". Para outro entrevistado,

Hoje está mais difícil caçar e pescar. Alguns estão dizendo que a mata continua grande, mas tem poucos animais. Os jovens têm se dedicado bastante à caça. Como é difícil encontrar caça, fica mais difícil ver os animais mais certos para caçar (Entrevistado 04).

A impressão sobre a redução dos estoques de fauna provocou um insipiente movimento de afastamento das famílias dos centros das comunidades, levando-as a optarem pela construção de moradias nos arredores dos locais de caça e pesca. Essa mudança parece se relacionar com as ideias de Dorst (1973) e Acton (1984), quando afirmam que o excesso de população pode ter profundas implicações no comportamento humano. Para um dos entrevistados,

Minha mãe diz que antigamente era mais fácil de conseguir caça, não
precisava ir tão longe. Como aumentou a população, as pessoas passaram
a ocupar outros lugares para morar, formando mini comunidades nos locais
de caça. Assim, aqueles que moram no centro da comunidade sentem
dificuldade para encontrar caça porque os que moram mais perto dos locais
de caça chegam antes para pegar a caça. A mesma situação acontece com
a pesca. Algumas famílias fizeram suas casas nas margens dos rios. Assim,
eles são os primeiros a pescar (Entrevistado 06).

Embora tenha aumentado a pressão sobre a fauna, o montante capturado ainda permanece aquém das demandas alimentares desses indígenas. A situação de insuficiência também se verifica na produtividade das roças e nas limitações ambientais para a ampliação das áreas cultivadas.

Produtividade das roças

Enquanto o crescimento populacional suscitou o aumento das áreas cultivadas, as concentrações populacionais nos centros das comunidades provocaram aproximações maiores entre as roças. Na contramão dessas demandas ficaram as condições do ambiente, especialmente quando se considera a baixa fertilidade do solo, a fragilidade ambiental e a condição climática. 
Segundo Falcão (2016), mesmo utilizando as cinzas das queimadas como fertilizante, com o tempo esse efeito diminui, suscitando o abandono da área por um determinado período. Nesse processo conhecido como pousio, o tempo de interrupção do cultivo varia entre as roças abertas na floreta e aquelas situadas nas margens dos igarapés. Segundo um entrevistado,

O local da roça é usado umas três vezes. Quando o solo fica gasto, é preciso mudar o local da roça. Nas margens dos rios, o pousio varia de seis meses a um ano. Na mata, varia de três a cinco anos. Geralmente, as famílias possuem duas roças: uma na margem do rio, perto da comunidade, e outra na mata, mais longe da comunidade. Na mata dá quase tudo, mas é mais difícil de levar para a comunidade (Entrevistado 03).

Em meio ao aumento da demanda pela ampliação das áreas cultivadas, surgiu a constatação da insuficiência das áreas férteis. Para o Entrevistado 07, "a população está crescendo e a produção está diminuindo porque não tem tantas áreas férteis".

No que tange a fragilidade ambiental, Melo (2010) ressalta que as variações climáticas ocorridas ao longo do tempo geológico no nordeste de Roraima influenciaram a passagem de um clima semiárido pretérito para condições de precipitação mais acentuadas. Esse processo favoreceu o avanço do intemperismo químico e erosão, contribuindo para maiores riscos de degradação dos solos nas áreas de relevo mais acidentado, bastante comum no território Ingarikó.

Novas estratégias de combate à insegurança alimentar

Diante da urgência do combate à insegurança alimentar, grande parte das estratégias adotadas passaram a envolver o conhecimento e apoio dos brancos. As iniciativas têm envolvido a criação de animais, a aquisição de produtos da sociedade envolvente, a criação de um centro de produção de alimentos e a discussão do turismo.

Segundo Cruz (2005), a primeira experiência com a criação de animais havia sido iniciada no ano 2000, tendo sido abandonada pela falta de experiência dos indígenas e pela inospitalidade dos locais destinados ao manejo dos animais. Essa experiência, por sua brevidade e reduzido número de animais, não parece ter gerado impactos significativos ao ambiente. Segundo Dorst (1973), os problemas com a criação de animais costumam se manifestar pelo excesso.

Quanto ao aumento da aquisição de produtos dos brancos, Williams (2012) destaca um crescimento significativo a partir do ano de 2004, período no qual foi introduzido o dinheiro no território indígena. Para Rodrigues (2013), o dinheiro 
oriundo do recebimento de salários, aposentadorias e programas sociais trouxe empoderamento para uma parcela pequena do povo Ingarikó, favorecendo, assim, o individualismo e o consumismo.

Outra estratégia de enfrentamento da insegurança alimentar envolveu a criação do Centro de Referência de Produção Animal e Vegetal (Centro NUTRIR). Conforme Ingaricó (2018), essa espécie de fazenda modelo foi destinada à criação de animais e à produção de frutas, grãos, legumes e verduras. O local começou a ser estruturado no ano de 2014, contando com o apoio de algumas instituições.

Para apoiar o projeto, a FUNAI entregou aos Ingarikó 32 cabeças de gado e 75 cabeças de carneiro. Em outro convênio capitaneado por um deputado, foram adquiridos mais de trezentas cabeças de gado, além de materiais e equipamentos (Figura 02).

Figura 02- Centro NUTRIR

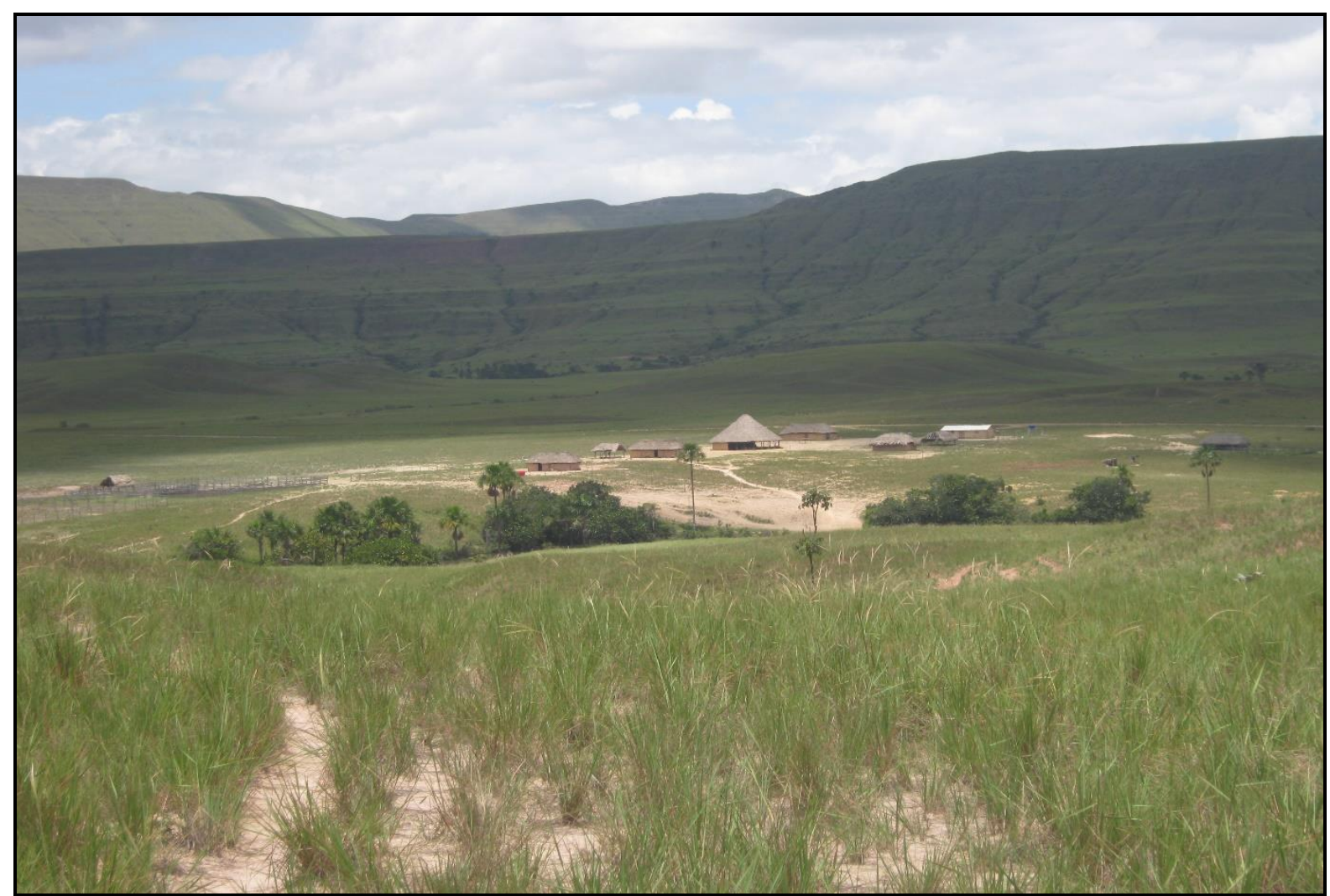

Fonte: O autor (2017)

No que tange o turismo, a primeira iniciativa permaneceu mais restrita a uma das comunidades. O estudo desenvolvido como trabalho de pesquisa de mestrado de Silva (2009) culminou com um plano de uso voltado à calha do rio Cotingo. Como na época o turismo em terras indígenas ainda era proibido, o plano não pôde ser executado. 
Alguns anos depois, já com outras comunidades envolvidas, os indígenas solicitaram apoio do poder público para o conhecimento e o desenvolvimento de atividades de turismo. Segundo Nogueira e Falcão (2011), as demandas foram inicialmente encaminhadas ao Serviço Brasileiro de Apoio às Micro e Pequenas Empresas (SEBRAE) e posteriormente repassadas ao Instituto Federal Educação, Ciência e Tecnologia de Roraima (IFRR).

Enquanto o IFRR começava a ministrar cursos voltados ao turismo, a FUNAI publicou a Instrução Normativa $\mathrm{n}^{\circ}$ 3, de 11 de julho de 2015, que estabeleceu normas e diretrizes relativas às atividades de visitação para fins turísticos em terras indígenas. Esse novo cenário possibilitou a contratação de um consultor para tratar especificamente da questão do turismo entre os Ingarikó. Os recursos provenientes do Projeto Ekurauyama foram viabilizados por uma articulação entre o Instituto Socioambiental (ISA) e a Embaixada da Noruega.

$\mathrm{Na}$ primeira oficina realizada entre os dias 01 e 04 de outubro de 2017, o consultor contratado promoveu discussões sobre a perspectiva do povo Ingarikó em relação ao turismo. Após as discussões sobre a repartição de benefícios, decisões e regras, novas atividades foram planejadas para o avanço na construção de uma proposta turística propriamente Ingarikó.

Ameaça à conservação da biodiversidade e à qualidade de vida dos indígenas

As intervenções do povo Ingarikó no ambiente costumam ser mais intensas nas proximidades das moradias. Porém, com o agravamento da insegurança alimentar, Falcão (2016) destaca que as atividades de caça e outras intervenções no ambiente passaram a ocorrer com maior intensidade em distâncias cada vez maiores das moradias.

Segundo Baniwa (2005) e Souza (2005), a visão romântica e idealizada de uma suposta vida indígena em harmonia com o ambiente sob quaisquer condições não se sustenta. Barreto Filho (2018) corrobora as afirmações anteriores ao destacar que não se pode esperar que naturalmente os originários se encarreguem da conservação do patrimônio natural. Para o autor, as ações dos povos indígenas permanecem sustentáveis enquanto a densidade demográfica se mantém baixa. Em situação oposta, podem ocorrer mudanças como as iniciadas entre os Ingarikó.

As condições vivenciadas pelos Ingarikó tornam o grupo cada vez mais vulnerável a propostas de apoio ao combate à insegurança alimentar pautadas em interesses escusos, como é o caso dos garimpeiros. Conforme depoimentos do 
Entrevistado 9, os garimpeiros já começaram a assediar algumas lideranças, tendo visitado o território para um primeiro reconhecimento do local. Diante do abandono da discussão sobre segurança alimentar dos diálogos com o ICMBio, a proposta de geração de renda apresentada pelos garimpeiros (e outras que possam surgir) apresenta um apelo crescente.

Nessas condições, a ampliação da perspectiva de gestão da área sobreposta também se torna urgente, pois pode recolocar o tema da segurança alimentar na pauta dos diálogos entre as partes. Essa providência também oferece respostas à conciliação dos interesses de proteção integral e usufruto indígena.

\section{NECESSIDADE DE AMPLIAÇÃO DA PERSPECTIVA DE GESTÃO}

Os dados obtidos por diferentes estratégias indicam a necessidade de ampliação da perspectiva de gestão a partir de três providências principais. A primeira consiste na associação entre as iniciativas ecológicas e sociais. A segunda envolve o reconhecimento das respectivas autonomias. Já a terceira requer a adoção de um processo de gestão pautada na organização conjunta.

\section{Associação entre as iniciativas ecológicas e sociais}

Para Aziz (2013), a conservação da biodiversidade em áreas ocupadas por indígenas demanda inicialmente o reconhecimento dos direitos dos autóctones sobre o uso dos bens naturais. Segundo o autor, a legislação aplicável deveria incluir provisões para a satisfação das necessidades dos indígenas. Caso contrário, os esforços empregados na proteção do ambiente terão poucas chances de êxito.

Conforme Schmidt e Peterson (2009), as estratégias de conservação que desconsideram os direitos e as necessidades dos povos indígenas normalmente se tornam prejudiciais à proteção dos componentes da biosfera. Entre os principais motivos constam os diversos papéis desempenhados pelos povos indígenas na proteção do ambiente.

Teixeira (2005) emprega a expressão naturalização do social para ilustrar processos de gestão de áreas sobrepostas nos quais as comunidades locais não são consideradas em suas especificidades. A priorização das iniciativas de cunho ecológico deixa tudo o que não diz respeito a esse tema em segundo plano. Essa perspectiva de concentração de esforços nos avanços das questões ecológicas corresponde ao mesmo tempo a tentativas de naturalização das populações 
envolvidas. Marra (2011) corrobora essa ideia ao defender a inclusão das questões sociais na gestão das áreas duplamente afetadas.

Ao analisar as ameaças à conservação da biodiversidade no Parque Nacional Canaima, situado em território venezuelano e contíguo ao PNMR, a organização Parkswatch (2004) considerou o crescimento demográfico como o principal desafio de gestão. Para fazer frente a essa situação, sugeriu a elaboração e execução de projetos voltados à qualidade de vida dos indígenas.

Outra questão importante diz respeito à insuficiência da demarcação de terras indígenas para o bem viver dos povos originários. Para Abi-Eçab (2008), a dignidade dos autóctones não pode ser assegurada apenas com o reconhecimento estatal dos seus territórios. Para Lima e Hoffmann (2002), deixar os indígenas resolverem todos os seus problemas constitui uma estratégia simplista.

Conforme Brasil (2014), na visão do próprio ICMBio as comunidades locais que mantêm relações de dependência com o ambiente, e não de exploração, possuem potencial para garantir a proteção da unidade de conservação. Até mesmo a Convenção da Diversidade Biológica incentiva a presença das populações tradicionais nos espaços especialmente protegidos, chegando a recomendar a permanência das formas tradicionais de uso dos bens naturais nas áreas sobrepostas.

Para Bensusan (2004), as unidades de conservação têm se revelado instrumentos limitados por não lidarem com a totalidade da gestão. Elas não abarcam o conjunto de ferramentas essenciais, capazes de garantir, ao longo do tempo, a manutenção da diversidade biológica.

A gestão da área sobreposta em questão suscita também a formação de uma parceria definida por Capra (2012) como verdadeira e confiante, capaz de propiciar a identificação das necessidades dos envolvidos e a construção de soluções compartilhadas. Esse nível de parceria perpassa o reconhecimento da autonomia indígena.

\section{Reconhecimento da autonomia indígena}

Desde o estabelecimento da sobreposição, quatro eventos importantes no histórico das relações entre o órgão ambiental e o povo indígena Ingarikó podem ser utilizados como exemplos das dificuldades ou avanços relacionados com a autonomia indígena. 
O primeiro evento diz respeito à elaboração do plano de manejo. Seguindo o padrão geral da categoria, e sem contar com a participação dos originários, as determinações do referido documento incluíram diversas restrições aos indígenas. Somente quando a construção do documento estava na fase final, alguns representantes do povo Ingarikó foram convidados a participar de uma oficina. O convite causou a impressão de ter sido feito com o único objetivo de atender a um requisito do processo de elaboração do plano de manejo. Como resultado, o plano de manejo provocou o estabelecimento de um conflito socioambiental.

O segundo evento teve um efeito bastante diferente em termos de gestão da área sobreposta. A determinação da construção de um plano de gestão conjunta previu como principal estratégia o reconhecimento da autonomia indígena. Esse contexto propiciou um processo de diálogos nos moldes descritos por Lalande (1999), envolvendo ações limitadoras da liberdade quistas livremente. Nos três anos dedicados à construção do Plano Paata Eseru, diversos consensos foram estabelecidos sobre a gestão da área sobreposta.

No entanto, os avanços conquistados foram interrompidos pelo terceiro evento, correspondente à imposição das condicionantes pelo STF. O cerceamento da autonomia indígena provocou uma descontinuidade do processo de negociações entre as partes envolvidas.

Num período de incertezas, o quarto evento, representado pela publicação do Decreto Decreto oㅜ 7.747, de 5 de junho de 2012, que instituiu a Política Nacional de Gestão Territorial e Ambiental de Terras Indígenas (PNGATI), ofereceu novas possibilidades de negociações entre as partes. As determinações da PNGATI possibilitaram a restauração do exercício da autonomia de ambas as partes, embora não tenha recuperado a divisão da responsabilidade pela gestão.

A breve apresentação desses quatro eventos explicita os avanços propiciados por estratégias de gestão pautadas no reconhecimento da autonomia indígena e as dificuldades provocadas por decisões unilaterais do poder público. Tais experiências demonstram que a perspectiva da gestão precisa partir da inexistência de qualquer determinação prévia de uma parte sobre a outra. Para Zatti (2007), essa constitui a principal condição de existência da autonomia. A despeito dos desafios, tal opção pode conduzir a uma parceria verdadeira e confiante pautada num processo de organização conjunta. 


\section{Processo de gestão pautado na organização conjunta}

A despeito das diversas terminologias utilizadas nas referências aos processos de gestão com duas ou mais partes envolvidas, torna-se necessário considerar os seus significados. Ao se referir ao PNMR, Scárdua (2004) chamou de cogestão a presença dos indígenas no conselho consultivo da unidade de conservação e a discussão entre as partes sobre os temas afetos ao modo de vida indígena. Nessa perspectiva, o significado de cogestão corresponderia à iniciativa do poder público de ouvir o povo Ingarikó, embora somente nos assuntos relacionados com o seu modo de vida.

Com uma perspectiva bastante diferente, Cardoso (2004) propôs outro significado à cogestão ao tratar da situação envolvendo o Parque Nacional Pacaás Novos e os povos indígenas Uru-Eu-Wai-Wai e Urupain. O autor defendeu um processo no qual as ações do poder público não tenham qualquer interferência nos interesses indígenas de usufruto dos bens naturais.

Para Simão e Fabré (2003), a cogestão deve propiciar o aproveitamento do conhecimento adquirido pelos grupos locais sobre o meio em que vivem. Em face dos vínculos afetivos e a história da ocupação, usos e defesa do território guardada na memória, essa ideia de gestão inclui a proposta de manutenção da estrutura tradicionalmente adotada pelas sociedades tradicionais.

Diferenças como essas tornam oportunas as considerações de Zurba (2012) sobre as tipologias de cogestão, gestão conjunta ou compartilhada. Uma delas seria equivalente a um sistema de troca de informações, mas sem a partilha de poder. Outro tipo seria aquele no qual o poder público deteria todos os direitos e conferiria às comunidades locais o direito de gerenciar os bens naturais. Há também a organização conjunta, na qual a autonomia indígena seria mantida e a conciliação entre os envolvidos se tornaria motivada pela colaboração mútua.

Considerando o contexto da sobreposição entre o PNMR e o território do povo Ingarikó, a tipologia mais adequada parece ser a organização conjunta. Tal noção viabiliza a conciliação de interesses entre a proteção integral dos componentes da biosfera e o usufruto indígena necessário à melhoria da sua qualidade de vida no âmbito da área sobreposta. 


\section{CONSIDERAÇÕES FINAIS}

As novas circunstâncias impostas pelo crescimento populacional e a sedentarização passaram a desafiar os antigos costumes do povo Ingarikó. Esses fenômenos se tornaram responsáveis pelo surgimento e agravamento de um quadro de insegurança alimentar. Ao perceberem a escassez de alimentos, os indígenas recorreram primeiramente aos líderes espirituais. Entretanto, diante da impossibilidade de resolução do problema por essa via, passaram a recorrer ao empirismo e às técnicas, recepcionando, assim, o conhecimento e o apoio dos brancos.

Com o estabelecimento da parceria com o órgão ambiental responsável pela gestão do parque nacional, o povo Ingarikó alimentou a expectativa de uma aproximação capaz de conjugar aspectos ecológicos e sociais, tornando-se capaz de superar os desafios das duas partes de forma colaborativa. Essa perspectiva perdurou por cerca de três anos, sendo obstaculizada pelas condicionantes impostas pelo STF.

Diante do abandono da discussão sobre segurança alimentar dos diálogos entre as partes envolvidas na sobreposição, os indígenas passaram a buscar novas alternativas. Essa iniciativa tornou os Ingarikó vulneráveis às propostas de grupos com diversos interesses. Serve como exemplo a aproximação iniciada pelos garimpeiros, que já começaram a visitar o território desses originários para avaliar as possibilidades de intervenção no ambiente.

Tais configurações da realidade suscitam a adoção de um processo de gestão mais abrangente, capaz de propiciar a conciliação de interesses sobre a área superposta. Numa perspectiva colaborativa como a da organização conjunta, as partes envolvidas teriam melhores condições de desenvolver uma parceria capaz de abarcar os diversos temas afetos à conservação da biodiversidade e à melhoria da qualidade de vida indígena, a exemplo da segurança alimentar.

\section{REFERÊNCIAS}

ABI-EÇAB, P. Presença indígena em unidades de conservação. 2008. 159 p. Dissertação (Mestrado em Direito das Relações Internacionais) - Pontifícia Universidade Católica de São Paulo, São Paulo, 2008.

ABREU, M. A. (Org.). Redistribuição, reconhecimento e representação: diálogos sobre igualdade de gênero. Brasília: IPEA, 2011. 222 p.

ACTON, R. The density syndrome. Rio de Janeiro: Eu e Você, 1984. 104 p. 
AZIZ, S. A. et al. Why Conservationists should be concerned about natural resource legislation affecting indigenous peoples' rights: lessons from Peninsular Malaysia. Biodivers Conserv, v. 22, p. 639-656. 2013.

BANIWA, G. Um "olhar indígena" sobre assistência técnica e extensão rural. In: VERDUM, Ricardo. (Org.). Assistência técnica e financeira para o desenvolvimento indígena: possibilidades e desafios para políticas públicas. Rio de Janeiro: Contra Capa Livraria, 2005. $162 \mathrm{p}$.

BARBOSA, J. B. F. Padrões de auto-regeneração de espécies dominantes em áreas de savana aberta em Roraima. In. BARBOSA, Reinaldo Imbrozio; MELO, Valdinar Ferreira. (Org.). Roraima: homem, ambiente e ecologia. Boa Vista: FEMACT, 2010. 644 p.

BARRETO FILHO, H. T. Reparação e descolonização como eixos da política indigenista: um trecho original do documento-base da $1^{\text {a }}$ Conferência Nacional de Política Indigenista. Vukápanavo: Revista Terena, v. 1, n. 1, p. 80-106, 2018.

BENSUSAN, N. Terras Indígenas: as primeiras Unidades de Conservação. In: RICARDO, F. (Org.). Terras Indígenas e Unidades de Conservação da Natureza: o desafio das sobreposições. São Paulo: Instituto Socioambiental, 2004. p. 66-72.

BRASIL. Decreto no 97.887, de 28 de junho de 1989. Cria o Parque Nacional do Monte Roraima e dá outras providências. Diário Oficial da República Federativa do Brasil, Brasília, DF, 29 jun. 1989.

BRASIL. Lei no 9.985, de 18 de julho de 2000. Institui o Sistema Nacional de Unidades de Conservação da Natureza e dá outras providências. Diário Oficial da República Federativa do Brasil, Brasília, DF, 19 ago. 2000.

BRASIL. Ministério do Meio Ambiente. Instituto Chico Mendes de Conservação da Biodiversidade. SOS Monte Roraima: Informações Gerais e Institucionais. Brasília: IBAMA, 2004. $91 \mathrm{p}$.

BRASIL. Decreto $\mathrm{s} / \mathrm{n}$. de 15 de abril de 2005. Homologa a demarcação administrativa da Terra Indígena Raposa Serra do Sol, localizada nos municípios de Normandia, Pacaraima e Uiramutã, no Estado de Roraima. Diário Oficial da União, Brasília, DF, 18 abr. 2005.

BRASIL. Ministério do Meio Ambiente. Instituto Chico Mendes de Conservação da Biodiversidade. Plano de Administração da Área sob Dupla Afetação pelo Parque Nacional Monte Roraima e a Terra Indígena Raposa Serra do Sol - Plano Pata Eseru. ICMBio: Brasília, 2008. 54 p.

BRASIL. Ministério do Meio Ambiente. Instituto Chico Mendes de Conservação da Biodiversidade. Povos indígenas, quilombolas, comunidades tradicionais, assentados da reforma agrária e unidades de conservação federais: diagnóstico e plano de ação para a gestão dos conflitos territoriais. Brasília: ICMBio, 2012. 109 p. Documento não publicado.

BRASIL. MINISTÉRIO PÚBLICO FEDERAL. Territórios de povos e comunidades tradicionais e as unidades de conservação de proteção integral: alternativas para 0 asseguramento de direitos socioambientais. Brasília: MPF, 2014. 117 p.

BRASIL. Instituto Brasileiro de Geografia e Estatística. Bases cartográficas. 2018. Disponível em: <www.ibge.gov.br>. Acesso em 11 dez. 2018a. 
BUTTO, A. Segurança alimentar indígena em dados. In: VERDUM, Ricardo. (Org.). Assistência técnica e financeira para o desenvolvimento indígena: possibilidades e desafios para políticas públicas. Rio de Janeiro: Contra Capa Livraria, 2005. 162 p.

CAPRA, F. A teia da vida: uma nova compreensão científica dos sistemas vivos. Trad. Newton Roberval Eichemberg. 13. ed. São Paulo: Cultrix, 2012. 256 p.

CARDOSO, I. B. Os Uru-Eu-Wau-Wau e a defesa do território. In: RICARDO, Fany (Org.). Terras indígenas e unidades de conservação da natureza: o desafio das sobreposições. São Paulo: Instituto Socioambiental, 2004. 690 p.

CRUZ, M. O. S. Fonologia e Gramática Ingarikó. Amsterdam: Vrije Universiteit Amsterdam, 2005. 464 p.

DORST, J. Antes que a natureza morra. Trad. Rita Buongermino. São Paulo: Edgard Blucher, 1973. 394 p.

FALCÃO, M. T. et al. Aptidão e uso agrícola na área Ingarikó - Terra Indígena Raposa Serra do Sol - Roraima. Revista Brasileira de Pós-Graduação. Brasília, v. 13, n. 32, p. 733-749, set./dez. 2016.

FRANK, E. H. Os Macuxi são mesmo "do Caribe"? Revista NUHSA, Boa Vista, v. 1, n. 2, p. 11-36, out. 2008.

FUNDAÇÃO ECOAMAZÔNIA. Evolução da população Ingarikó no norte e nordeste de Roraima. Boa Vista: Ecoamazônia, 2018. Disponível em: <www.ecoamazonia.org.br>. Acesso em 15 ago. 2018.

GALLOIS, D. T. Materializando saberes imateriais: experiências indígenas na Amazônia Oriental. Revista de Estudos e Pesquisas, Brasília, v. 4, n. 2, p. 95-116, dez. 2007.

INGARICÓ, B. E. Produção e alimentação no contexto social na comunidade indígena Manalai-RR. Boa Vista: UFFRR, 2012. 26 p. Trabalho de Conclusão de Curso (Graduação) Curso de Licenciatura Intercultural, Universidade Federal de Roraima, Boa Vista, 2012.

INGARICÓ, D. D. Saúde e nutrição nas comunidades indígenas: uma breve reflexão sobre a influência dos costumes não indígenas no cotidiano do povo Ingarikó. 2008. 51 p. Monografia (Graduação) - Curso de Licenciatura Intercultural, Universidade Federal de Roraima, Boa Vista, 2008.

INGARICÓ, L. M. S. Wekuik: o calendário cultural do povo Ingarikó. Boa Vista: UFRR, 2012. 70 p. Monografia (Graduação) - Curso de Licenciatura Intercultural, Universidade Federal de Roraima, Boa Vista, 2012.

INGARICÓ, S. S. E. Estratégia de etnodesenvolvimento do povo Ingarikó: estudo de caso do Centro de Referência de Produção Animal e Vegetal (NUTRIR). 2018. 39 p. Monografia (Graduação em Gestão Territorial) - Instituto Insikiran de Educação Superior Indígena, Curso de Gestão Territorial Indígena, Boa Vista, 2018.

KOSELLECK, R. Futuro passado: contribuição à semântica dos tempos históricos. Rio de Janeiro: PUC, 2006.

LALANDE, A. Vocabulário técnico e crítico da filosofia. Tradução Fatima Sa Correia et al. 3. ed. São Paulo: Martins Fontes, 1999. 1336 p. 
LAURIOLA, V. M. De quem é o Monte Roraima? Terras indígenas e unidades de conservação entre os dilemas da conservação na Amazônia brasileira. Passages de Paris, p. 53-110, 2011.

LIMA, A. C. S.; HOFFMANN, Maria Barroso. (Org.). Estado e povos indígenas: bases para uma nova política indigenista II. Rio de Janeiro: LACED, 2002. 112 p.

LITTLE, P. E. Ecologia política como etnografia: um guia teórico e metodológico. Horizontes Antropológicos, Porto Alegre, v. 12, n. 25, p. 85-103, jan./jun. 2006.

MAHFOUD, M.; MASSIMI, M. A pessoa como sujeito da experiência: contribuições da fenomenologia. Memorandum, Belo Horizonte, n. 14, p. 52-61, 2008.

MARRA, N. C. Identidades culturais e a sustentabilidade na criação de parques ambientais. Revista Prisma Jur., v. 10, n. 2, p. 349-367, jul./dez. 2011.

MELO, V. F. et al. Aspectos pedológicos e de manejo dos solos de Roraima. In. BARBOSA, Reinaldo Imbrozio; MELO, Valdinar Ferreira. (Org.). Roraima: homem, ambiente e ecologia. Boa Vista: FEMACT, 2010.644 p.

MLYNARZ, R. B. Parque Nacional do Monte Roraima: constituindo a arena de negociação política dos Ingarikó frente à conservação da natureza, em terra indígena. In: Encontro da ANPPAS, 3, 2006, Brasília/DF. Anais... Brasília, ANPPAS, 2006. 14 p.

MLYNARZ, R. B. Processos Participativos em Comunidade Indígena: um estudo sobre a ação política dos Ingarikó face à conservação ambiental do Parque Nacional do Monte Roraima. 2008. 141p. Dissertação (Mestrado em Ciência Ambiental) - Programa de PósGraduação em Ciência Ambiental, Universidade de São Paulo, São Paulo, 2008.

NOGUEIRA, E. M.; FALCÃO, M. T. Serra do Sol: o turismo de base local como fonte de desenvolvimento das comunidades. Revista Geográfica de América Central, Costa Rica, número especial, p 1-13, jul./dez. 2011.

PAGLIARO, H. A revolução demográfica dos povos indígenas: a experiência dos Kaiabi do Parque Indígena do Xingu, Mato Grosso. In: PAGLIARO, H.; AZEVEDO, M. M.; SANTOS, R. V. (Org.). Demografia dos povos indígenas no Brasil. Rio de Janeiro: FIOCRUZ, 2005. $192 \mathrm{p}$.

PARKSWATCH. Perfil de área protegida: Parque Nacional Canaima (setor oriental). Ciudad Bolívar/Venezuela: Parkswatch, 2004. 32 p.

PULIDO, C. B. O conceito de liberdade na teoria política de Norberto Bobbio. Tradução Julio Pinheiro Faro Homem de Siqueira. [S.I.]: Revista de Economía Institucional, 2006. 24 p.

REGALIA, I. Dicionário de Política. Brasília: UnB, 2012.

RODRIGUES, E. S. Economia e Produção Ingarikó. 2013.160 p. Dissertação (Mestrado em Antropologia Social) - Programa de Pós-Graduação em Antropologia Social, Universidade Federal de Pernambuco, Recife, 2013.

RODRIGUES, P. C.; FERREIRA, R. R. Sobreposição de unidades de conservação em terras indígenas no estado de Roraima. In: VITA, Jonathan Barros.; NASCIMENTO, Valéria Ribas do.; RIBEIRO, Daniela Menengoti. (Org.). Direitos fundamentais e democracia II. Florianópolis: FUNJAB, 2013. p. 303-317. 
RORAIMA. Secretaria de Desenvolvimento e Planejamento. Base cartográfica. Boa Vista: SEPLAN, 2017.

SCÁRDUA, F. P. Manejo Sustentável no Parna do Monte Roraima e na TI Raposa/Serra do Sol. In: RICARDO, F. (Org.). Terras Indígenas e Unidades de Conservação da Natureza: o desafio das sobreposições. São Paulo: Instituto Socioambiental, 2004. p. 432-435.

SCHMIDT, P. M.; PETERSON, M. J. Biodiversity Conservation and Indigenous Land Management in the Era of Self-Determination. Consevation Biology, n. 6, v. 23, p. 14581466. 2009.

SILVA, E. L. S. Plano de uso público do Parque Nacional do Monte Roraima: proposta de estruturação de uma cadeia produtiva de ecoturismo na calha do rio Cotingo, com base nos princípios da Economia Ecológica. 2009. 106 p. Dissertação (Mestrado em Economia) Programa de Pós-Graduação em Economia, Universidade Federal do Rio Grande do Sul, Porto Alegre, 2009.

SIMÃO, M. O. A. R.; FABRÉ, N. N. (Org.). Sistemas Abertos Sustentáveis (SAS): uma alternativa para a gestão ambiental na Amazônia. Manaus: EDUA-UFAM, 2003.

SOUZA, M. A. O PRONAF e os povos indígenas. In: VERDUM, Ricardo. (Org.). Assistência técnica e financeira para o desenvolvimento indígena: possibilidades e desafios para políticas públicas. Rio de Janeiro: Contra Capa Livraria, 2005. 162 p.

TEIXEIRA, C. O desenvolvimento sustentável em unidades de conservação: a naturalização do social. Revista Brasileira de Ciências Sociais, São Paulo, v. 20, n. 59, p. 51-66, out. 2005.

TEIXEIRA, M. Educação escolar na comunidade de Serra do Sol. Boa Vista: UFRR, 2008. 39 p. Trabalho de Conclusão de Curso (Graduação) - Curso de Licenciatura Intercultural, Universidade Federal de Roraima, Boa Vista, 2008.

WHITEHEAD, N. L. Dark Shamans: kanaima and the poetics of violent death. Durham/NC: Ducke University, 2002.

WILLIAMS, S. C. A valorização de conhecimentos tradicionais do povo Ingarikó. Boa Vista: UFRR, 2012. 47 p. Trabalho de Conclusão de Curso (Graduação) - Curso de Licenciatura Intercultural, Universidade Federal de Roraima, Boa Vista, 2012.

ZATTI, V. Autonomia e educação em Immanuel Kant e Paulo Freire. Porto Alegre: EDIPUCRS, 2007. 83 p.

ZURBA, M. et al. Building co-management as a process: problem solving through partnerships in aborígene country, Australia. Environmental Management, n. 49, p. 11301142, 2012.

\section{NOTAS DOS AUTORES}

\section{CONTRIBUIÇÃO DE AUTORIA}

Oseias Cordeiro Sartori - Concepção. Coleta de dados, Análise de dados, Elaboração do manuscrito, revisão e aprovação da versão final do trabalho

Henrique dos Santos Pereira - Concepção e elaboração do manuscrito. Coleta de dados Participação ativa da discussão dos resultados; Revisão e aprovação da versão final do trabalho. 
FINANCIAMENTO

Não se aplica.

CONSENTIMENTO DE USO DE IMAGEM

Não se aplica.

\section{APROVAÇ̃̃O DE COMITÊ DE ÉTICA EM PESQUISA}

A pesquisa foi aprovada pela Comissão Nacional de Ética em Pesquisa (CAAE 67016717.0.0000.5020 / Parecer 2.255.365 / Aprovada em 02 de setembro de 2017) e pela FUNAI (Autorização no 50/AAEP/PRES/2017).

\section{CONFLITO DE INTERESSES}

Não se aplica.

\section{LICENCA DE USO}

Este artigo está licenciado sob a Licença Creative Commons CC-BY. Com essa licença você pode compartilhar, adaptar, criar para qualquer fim, desde que atribua a autoria da obra.

\section{HISTÓRICO}

Recebido em: 15-11-2018

Aprovado em: 09-06-2020 